\title{
When the world needs to know
}

\author{
Was the public re-release of data excerpts from an unpublished manuscript on human germline gene editing \\ ethically justified?
}

M ore than a year has passed since Jiankui He announced that he had used CRISPR-Cas9 to edit the DNA of numerous human embryos, at least two of which were claimed to have gestated into twin baby girls. Widely and justifiably derided, He's experiment was poorly conceived, shoddily executed and inappropriately consented. It was not only a reckless ethical disaster but also a scientific mess and a blemish on the field of gene editing. Now, excerpts of an unpublished paper associated with He's work have been released both in a new book and in one of three related news articles posted on 3 December by MIT Technology Review. The authors' justification provided for releasing these excerpts-including re-release of data originally disclosed by He himself at a talk at the 2nd International Genome Editing Summit in Hong Kong in November 2018 is that the world needs to know. But it is far from evident that much new information has been learned, and the decision to re-publish chromatograms from the two embryos without re-consent ignores the privacy rights of the gene-edited baby girls.

MIT Technology Review investigative journalist Antonio Regalado originally broke news of He's experiments in November 2018. Early in 2019, he obtained a copy of an unpublished paper pertaining to the work, which he later shared with Kiran Musunuru, a cardiologist at the University of Pennsylvania and a somatic-cell geneediting expert. According to Musunuru, the understanding was that he was free to publish portions of the paper in his forthcoming book, The CRISPR Generation. MIT Technology Review also published a set of stories related to the unpublished paper, including one containing excerpts of the paper's text and data critiqued by four experts, and an op-ed article from Musunuru.

The central mechanism for public release of the excerpts without He's permission is 'fair use'-a legal principle that can be used to circumvent obtaining copyright permission from the content's originator. A legal challenge in US courts to establish whether the excerpts meet the requirements of fair use seems unlikely, given that He has received a three-year prison sentence and fine of 3 million yuan for "illegal medical practices" from a Shenzhen court. Musunuru believes that including the data excerpts in his book meets the standard of public interest because ethical flaws in the work preclude its publication in more traditional forums such as peer-reviewed journals or preprint servers.

In terms of new information gleaned from the excerpts, we learn that the fertility doctors who undertook the in vitro fertilization procedure were not named as authors on the unpublished paper-a highly unusual practice for a human research study, thus raising questions of whether the clinical team knew that the embryos were gene-edited. The paper's acknowledgments also reveal the involvement of an equinereproduction specialist, W. R. 'Twink' Allen; Allen's former student John Zhang is head of the New Hope Fertility Center in New York, which according to a Science news report was negotiating with He to open a medicaltourism business for gene-edited babies.

All the other excerpts merely add detail to what we already knew. Musunuru also notes that inclusion of the embryo chromatogram-sequence information in his book was necessary because, although it was shown at He's talk at the Hong Kong summit, it was 'blink and you'll miss it'. Musunuru also argues that a CRISPR Journal commentary (https://doi.org/10.1089/ crispr.2018.29039.spr) also partly disclosed the information. That may be so, but it still seems problematic that both Musunuru and MIT Technology Review simply elected to reproduce the chromatogram imagesdivulging the sequence of 52 bases at CCR5 in each of the embryos-when they could have redacted the sequence data and still shown the extent of mosaicism.

In his op-ed article, Musunuru argues that re-publication was warranted because it provides further evidence and detail to counter rumors that He's experiments were a hoax. Musunuru also points out that the international committees convened by the World Health Organization, the US National Academies of Medicine and Sciences, and the Royal Society currently have no access to the details in He's unpublished paper. Similarly, he asks how the Russian regulatory authorities can "properly evaluate Denis Rebrikov's purported germline gene-editing efforts, if the nature of the problems with He's work aren't widely known." But why not simply send the unpublished paper to regulators in confidence?

Another complication of this story is the excerpts' murky provenance. Because Regalado has not revealed his sources, we have to take Musunuru's word that they are authentic. In his book, he reveals that Associated Press journalist Marilynn Marchione previously provided him with a copy of the paper. Ultimately, we are left with excerpts of an unpublished paper of unverified provenance, in which the data are without context and inadequately described, with no known connected protocol or indeed any person with firsthand knowledge who is willing to describe the protocol.

Many bioethicists interviewed by Nature Biotechnology felt that publishing in this manner was voyeuristic and unethical. But that view is not universally held; a majority of people polled on social media supported the exposé: on Twitter, $66 \%$ of 522 people indicated that publication was justified.

The larger question here is what to do with ethically compromised research of public interest that cannot be published through traditional venues, such as journals or preprints. One possibility suggested by the Wyss Institute's Jeantine Lunshof would be to publish such research on the publishing-integrity site Retraction Watch, with ethically problematic information redacted or reconsented.

Journalism is always another route. But public disclosure should never trump protections given to human research participants without due cause (for example, evidence of a crime). In this case, publication seems to have overlooked the privacy rights of two innocent human beings simply because the world 'needed to know'.

Published online: 9 January 2020 https://doi.org/10.1038/s41587-019-0396-4 